\title{
Beoordelen van opleiders door arts-assistenten
}

\author{
E.R. Flikweert • M.T. Miedema • J.W. Briët
}

Samenvatting Inleiding: Het beoordelen van medisch specialisten in hun rol als docent staat de laatste jaren meer in de belangstelling. Doel hiervan is de kwaliteit van de opleiding te verbeteren. In het Deventer Ziekenhuis werd een start gemaakt met een ziekenhuisbrede, gestructureerde beoordeling van opleiders door hun artsassistenten.

Methode: Er werd een vragenlijst opgesteld met 28 vragen, waarmee de kwaliteiten van de opleider als docent en als rolmodel werden gescoord. De uitkomst hiervan werd door de artsassistenten met elke opleider persoonlijk besproken. Verder werd door de arts-assistenten een lijst ingevuld over het proces van leren van de competenties zoals opgesteld door het Centraal College Medische Specialismen (CCMS) en zijn de beoordelingsgesprekken geëvalueerd.

Resultaten: Aan dit onderzoek deden 45 arts-assistenten van 7 vakgroepen mee. De vragenlijst voldeed aan de bedoeling om een breed oordeel over de opleider te vormen. Voor latere beoordelingen werd de vragenlijst geëvalueerd en aangepast. De arts-assistenten bleken de verschillende competenties met dezelfde methoden te verwerven: zowel de meester-gezelrelatie en de observatie van een rolmodel als eigen ervaring.

Discussie: De aangepaste vragenlijst blijkt geschikt als basis voor een beoordelingsgesprek. De beoordelingsgesprekken bleken voor beide partijen een positieve ervaring. Uit de literatuur blijkt dat herhaalde beoordeling een betere kwaliteit van medisch specialisten als opleider oplevert. In de toekomst zullen de beoordelingen herhaald moeten worden om effect waar te nemen.

Conclusie: Het beoordelingsinstrument is bruikbaar voor alle specialistenopleidingen. Gestructureerde feedback geven is een positieve ervaring voor zowel opleiders als arts-assistenten. (Flikweert ER, Miedema MT, Briët
JW. Beoordelen van opleiders door arts-assistenten. Tijdschrift voor Medisch Onderwijs 2007;26(1):3-10.)

\section{Inleiding}

Er is veel belangstelling voor de professionalisering van docenten in het klinisch onderwijs.1-5 Een medisch specialist is niet vanzelfsprekend ook een goede docent. Het is begrijpelijk dat er ook meer aandacht is voor de beoordeling van medisch specialisten in hun rol van docent.610 Deze beoordeling zou mede door artsassistenten gedaan kunnen worden. Hoewel het als normaal wordt beschouwd dat een arts-assistent met enige regelmaat door zijn opleider beoordeeld wordt, is een omgekeerde rolverdeling niet vanzelfsprekend.

Een goede opleider zal zijn begeleiding van de assistent in opleiding tot specialist (aios) aanpassen aan de klinische context, de zelfstandigheid en leerstijl van de assistent en aan de aard van de te verwerven competenties. Praktische vaardigheden worden geleerd onder directe supervisie, meer algemene competenties worden geleerd door observatie van een rolmodel, kennis door studie en tenslotte wordt men pas echt bekwaam door ervaring op te doen. Het is de vraag hoe de didactische kwaliteiten van een opleider in deze verschillende situaties het beste kunnen worden beoordeeld.

Hiervoor zijn de afgelopen jaren meerdere vragenlijsten ontwikkeld. In Cleveland is een vragenlijst ontwikkeld waarmee de onderwijskwaliteiten van de medische staf beoordeeld werden door arts-assistenten met als doel deze kwaliteiten te verbeteren.7 Deze lijst is veel gebruikt en is gevalideerd en betrouwbaar. Enige jaren later publiceerde de vakgroep Chirurgie van het Canisius- 
Tabel 1. De oorspronkelijke en de aangepaste vragenlijst.

Oorspronkelijke versie Uiteindelijke versie

Als docent

Algemeen

Medisch handelen

\section{Als rolmodel \\ Communicatie}

Samenwerking en

organisatie

Kennis en wetenschap

\section{Maatschappelijk}

handelen

Professional(iteit)
1. Vestigt een goede leeromgeving

(enthousiast, toegankelijk, veilig, et cetera)*

2. Stimuleert tot onafhankelijk leren; motiveert*

3. Bevordert mijn autonomie in relatie tot mijn bekwaamheid; stimuleert ontplooiing*

4. Organiseert tijd voor zowel onderwijs als begeleiding (mentor)* 5. Geeft regelmatig feedback $(+ \text { en }-)^{*}$

6. Specificeert wat men verwacht dat ik doe en weet*

7. Laat onderwijs aansluiten bij mijn behoefte (ervaring, bekwaamheid, belangstelling en leerstijl)*

8. Stelt stimulerende vragen (verheldert, peilt, Socratische discussie, reflectieve vragen, et cetera)*

9. Begeleiding t.a.v. patiëntenzorg\#

10. Begeleiding operatie-technisch\#

11. Overbrengen vakinhoudelijke kennis\#

12. Geeft heldere uitleg/verklaring voor opvattingen, advies, handelingen, et cetera*

13. Past onderwijs aan aan setting (spreekkamer, OK, visite, microscoop, et cetera)*

14. Coacht in klinische en technische vaardigheden (anamnese, onderzoek, diagnostiek, procedures, lab, et cetera)*

15. Leert diagnostische vaardigheden

(klinisch redeneren, keuze en interpretatie van tests, et cetera)*

16. Verslaglegging\#

17. Relatie met patiënten\#

18. Relatie met assistenten\#

19. Toont effectieve communicatie met patiënt en/of familie\#* 20. Relatie met andere medewerkers\#

21. Samenwerking en teambuilding\#

22. Planning en organisatie\#

23. Begeleiding wetenschappelijk

onderzoek\#

24. Past uitkomsten van research en richtlijnen en protocollen toe in onderwijs

25. Toont principes van kostenbewust handelen*

26. Betrekt maatschappelijke context in patiëntenzorg* 27. Professionele uitstraling\#
1. Vestigt een goede leeromgeving (enthousiast, toegankelijk, veilig, et cetera)

2. Stimuleert ontplooiing en bevordert automie in het nemen van onafhankelijke beslissingen. Motiveert tot onafhankelijk

leren, aansluitend bij mijn behoefte (ervaring, bekwaamheid, belangstelling en leerstijl)

3. Organiseert tijd voor zowel onderwijs als begeleiding (mentor) 4. Geeft regelmatig feedback ( + en -)

5. Specificeert wat men verwacht dat ik doe en weet

6. Stelt stimulerende vragen (verheldert, peilt, Socratische discussie, reflectieve vragen, et cetera)

7. Begeleiding t.a.v. patiëntenzorg

8. Begeleiding operatie-technisch/andere invasieve handelingen

9. Overbrengen vakinhoudelijke kennis

10. Geeft heldere uitleg/verklaring voor opvattingen, advies, handelingen, et cetera

11. Coacht in klinische en technische vaardigheden (anamnese, onderzoek, diagnostiek, procedures, lab, et cetera)

12. Leert diagnostische vaardigheden

(klinisch redeneren, keuze en interpretatie van tests, et cetera)

13. Verslaglegging

14. Relatie met assistenten

15. Toont effectieve communicatie met patiënt en/of familie

16. Relatie met andere medewerkers; samenwerking en teambuilding

17. Planning en organisatie

18. Begeleiding wetenschappelijk

onderzoek

19. Past uitkomsten van research en richtlijnen en protocollen toe in onderwijs

20. Toont principes van kostenbewust handelen

21. Betrekt maatschappelijke context in patiëntenzorg 22. Levert hoogstaande patiëntenzorg 
Tabel 1. (continued)

\begin{tabular}{lr}
\hline & Oorspronkelijke versie \\
\hline Uiteindelijke versie \\
woorde wijze \\
* Vraag afkomstig van de lijst uit Cleveland; \# Overgenomen van de lijst uit Nijmegen. & $\begin{array}{r}\text { 23. Toont adequaat professioneel gedrag } \\
\text { 24. Kent grenzen van eigen competentie } \\
\text { 25. Is ook in algemene zin een goed rolmo- } \\
\text { del voor de arts-assistenten }\end{array}$ \\
\end{tabular}

* Vraag afkomstig van de lijst uit Cleveland; \# Overgenomen van de lijst uit Nijmegen.

Wilhelmina Ziekenhuis de eerste positieve ervaringen met de evaluatie van opleiders door hun eigen arts-assistenten.11 In navolging hiervan, met het doel de kwaliteit van de opleiding te verbeteren, is in het Deventer Ziekenhuis een start gemaakt met een gestructureerde beoordeling van opleiders bij diverse vakgebieden. Nevendoel voor de arts-assistenten is het verwerven van inzicht in het eigen leerproces. De volgende vragen zijn geformuleerd:

1. Is het mogelijk een vragenlijst te ontwikkelen waarmee in het hele ziekenhuis arts-assistenten feedback kunnen geven aan hun opleiders en voldoet dit in de praktijk?

2. Op welke manier verkrijgt een arts-assistent bepaalde competenties en wat is de betekenis van de docent hierbij?

\section{Methode}

Om de kwaliteiten van de opleiders te beoordelen, is een instrument ontwikkeld dat bestaat uit 28 vragen (tabel 1, linker kolom). De vragen zijn gebaseerd op de Cleveland Clinic's Clinical Teaching Effectiveness Instrument, de vragen van het Canisius Ziekenhuis te Nijmegen en de zeven competenties die een medisch specialist moet kunnen vervullen, zoals in 2004 door het Centraal College Medische Specialismen (CCMS) is vastgesteld.7 11-12 Deze competenties luiden: medisch handelen, communicatie, samenwerking, kennis en wetenschap, maatschappelijk handelen, organisatie en professionaliteit. De helft van de vragen betreft didactische vaardigheden, zowel algemene als medisch- technische, waarmee de opleider op zijn kwaliteiten als docent wordt beoordeeld. De andere vragen betreffen de voorbeeldfunctie van de opleider, namelijk het rolmodel.

Er werd gescoord op een 5-puntsschaal, van 'opvallend goed' tot 'slecht'. Tevens kon 'niet van toepassing' ingevuld worden. Elke arts-assistent vulde de lijst in voor al zijn opleiders. Per opleider werd een gemiddelde score uitgerekend. Namens de assistentengroep van een specialisme bespraken twee vertegenwoordigers de uitkomsten met elke opleider individueel. Om alle vakgroepen te bereiken is voor deze evaluatie instemming verkregen van de centrale opleidingscommissie van het Deventer Ziekenhuis, waarin de opleiders van alle vakgroepen en vertegenwoordigers van de arts-assistenten zitting hebben.

$\mathrm{Na}$ afloop van elk beoordelingsgesprek gaven de twee arts-assistenten in een gestructureerde vragenlijst hun mening over het verloop en het mogelijke nut van het gesprek. Er werd een lijst met tien vragen ingevuld waarbij 'ja' of 'nee' aangekruist moest worden. Een voorbeeld van deze vragen is: "Was het gesprek relevant, constructief en niet-kwetsend?" Tevens is eenmalig gevraagd aan te geven wat de meest geschikte groepssamenstelling en frequentie van de beoordelingsgesprekken zouden zijn.

Omdat de invloed van de opleiders op het leren van de arts-assistent behalve van de docent ook afhankelijk is van de wijze waarop iemand leert (diens leerstijl) en van de aard van de competentie en de context, is de deelnemende arts-assistenten gevraagd hoe zij dachten zich de competenties zoals opgesteld door het CCMS eigen te maken: in de meester-gezelrelatie, via de opleider als rolmodel of door eigen ervaring (tabel 2). De relevantie van elke leermethode moest op een 5-puntsschaal aangegeven worden (1: heel weinig; 5: heel veel). Deze tabel werd door de artsassistenten van elke vakgroep gezamenlijk eenmalig ingevuld.

\section{Resultaten}

De keuze van de vragen is in de eerste plaats bepaald door de goede ervaringen met de vijftien vragen van het Cleveland Clinic's Clinical Teaching Effectiveness Instrument. 7 Van de vragenlijst uit Nijmegen zijn ook vragen overgenomen.11 In de tabel is de herkomst van de vragen weergegeven. De indeling van de vragen is bepaald door de zeven competentiegebieden zoals vastgesteld door het CCMS, waarbij 'samenwerking' en 'organisatie' werden samengevoegd. De uiteindelijke vragenlijst zoals deze gebruikt is in het Deventer Ziekenhuis, is opgesteld door de auteurs van dit artikel.

Nadat de beoordelingsgesprekken hadden plaatsgevonden is de vragenlijst door vertegenwoordigers van 
Dit formulier in te vullen door elke arts-assistent.

Bijdrage aan opleiding:

1. De meester-gezel relatie.

2. De docent als rolmodel.

3. Eigen ervaring.

Geef aan in hoeverre je bekwaamheid in het vervullen van de 7 Can/MEDS rollen toeneemt ten gevolge van on derwijs dat specifiek op die rol is gericht, door afkijken van de kunst bij je opleiders, of door eigen ervaring:

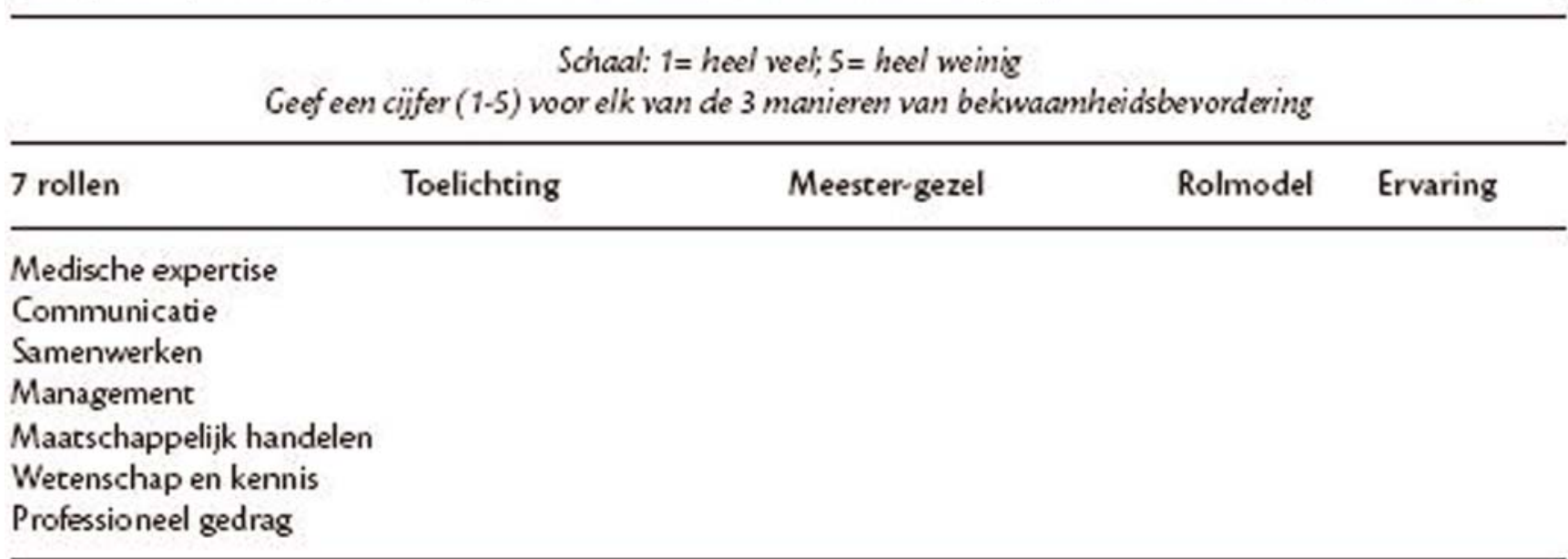

Tabel 2 Formulier voor de wijze van leren van de verschillende competenties.

alle vakgroepen, waaronder de auteurs, geëvalueerd. Vervolgens is de lijst aangepast omdat sommige vragen niet goed van elkaar te onderscheiden waren, de vraag niet voor elke vakgroep relevant was of om duidelijker de verschillende competenties een plaats te geven. De aangepaste vragenlijst vormt de rechter kolom van tabel 1 .

Het verder uitbreiden van de vragenlijst wordt niet zinvol geacht, omdat met de huidige vragen een brede beoordeling gegeven kan worden.

De evaluaties vonden plaats in de opleidingen tot chirurg, internist, kinderarts, gynaecoloog, orthopedisch chirurg, uroloog en ziekenhuisapotheker. De beoordelingslijst is ingevuld door 45 arts-assistenten, waarbij 51 opleiders zijn beoordeeld, verdeeld over 7 vakgroepen. Slechts één vakgroep ( 5 arts-assistenten) heeft besloten niet mee te doen. Het aantal beoordelingsformulieren dat per opleider is ingevuld, verschilde al naar gelang de grootte van de vakgroep (2 tot 15 arts-assistenten). De gesprekken bleken relevant en constructief. Een gesprek tussen twee arts-assistenten en één opleider werd door iedereen als beste vorm ervaren. Verder gaf men aan te verwachten dat de docentenrol meer door middel van gestructureerde feedback zou kunnen verbeteren dan het professioneel gedrag van de opleider en dat herhaalde feedback effectiever is dan een eenmalige beoordeling.

De zeven deelnemende vakgroepen leverden elk een gezamenlijk ingevulde vragenlijst over het proces van leren van de verschillende competenties in (tabel 2). Bij elke vakgroep bleek dat alle drie de leermethoden (meester-gezel, rolmodel en eigen ervaring) bijdroegen aan het verwerven van de zeven competenties. Figuur 1 toont de waarden die de totale assistentengroep toekende aan de verschillende methoden van leren van de algemene competenties. Hieruit blijkt dat voor alle competenties het belang dat aan de verschillende leermethoden wordt toegekend niet veel verschilt. Bij het verwerven van expertise is de directe invloed van de opleider het grootst. Verder zijn de assistenten van mening dat het zelf opdoen van ervaring de belangrijkste bijdrage levert aan hun opleiding. De docent als rolmodel is vooral van betekenis op het gebied van maatschappelijk handelen en professioneel gedrag.

\section{Discussie}

Met het vrijwel ziekenhuisbreed invoeren van de beoordelingen van opleiders door arts-assistenten is in ons ziekenhuis een nieuw licht geworpen op het ideale opleiderschap. Arts-assistenten zitten in een afhankelijke positie en zullen daardoor niet snel een oordeel vellen over hun opleider. Door structuur te geven in een vragenlijst en als groep een oordeel te vormen, bleek het wel mogelijk feedback te geven. Alle 


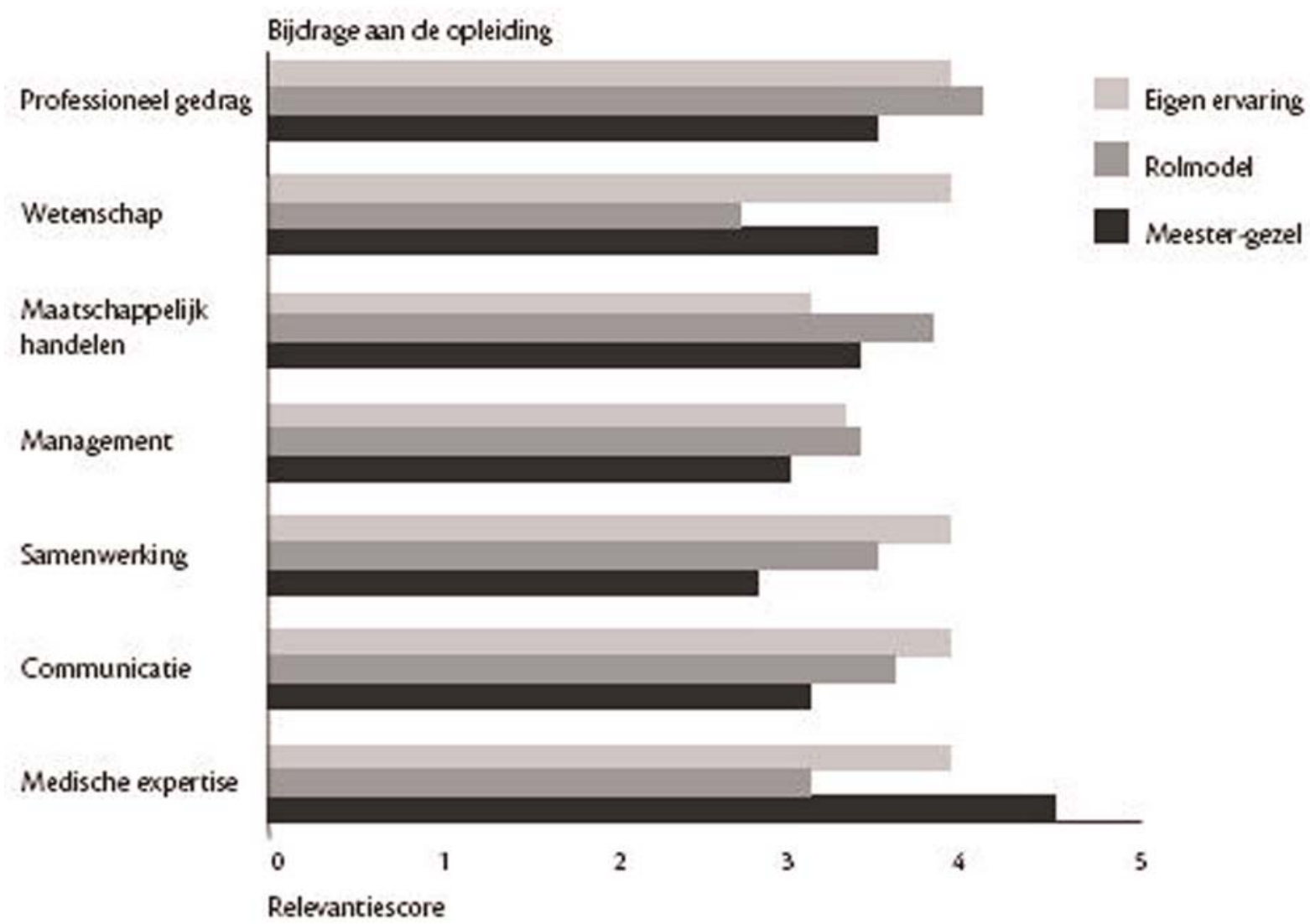

Figuur 1 Bijdrage van de verschillende leermethoden aan het leren van competenties.

vakgroepvertegenwoordigers gaven achteraf aan dat de gesprekken minder bedreigend waren dan verwacht en regelmatig leidden tot onverwacht goede gesprekken over opleiden. De opleiders werden zich bewust van bepaalde positieve en negatieve aspecten van hun invulling van het opleiderschap en er zijn duidelijk veranderingen in gedrag waargenomen. Hoewel de effecten niet gemeten zijn, werd door de arts-assistenten aangegeven dat zij gedurende de beoordelingsronden beter zijn geworden in het effectief feedback geven. Verder gaven zij aan nu meer na te denken over aspecten die belangrijk zijn in een opleidingssituatie.

De vragenlijst die wij ontwikkelden lijkt een geschikt instrument voor deze beoordeling. De lijst is uitgebreid. Hierdoor is het mogelijk niet alleen op het gebied van medisch handelen goede van middelmatige docenten te onderscheiden, maar ook een breder oordeel te vellen over de meer sociale aspecten van de docent als rolmodel. 13-19 Tevens wordt nadruk gegeven aan de verschillende competenties zoals deze onderwezen dienen te worden.20 Tijdens de evaluatie is aangegeven dat de lijst vaak als leidraad gebruikt is om de feedback duidelijk over te brengen. Er zijn in de gesprekken dan ook meer zaken besproken die soms als losse opmerkingen door de artsassistenten bijgeschreven waren.

Hoewel het aantal beoordelingen relatief klein is en onze ervaring gering, zijn de positieve effecten, zoals die waargenomen zijn, zo groot dat de vragenlijst toepasbaar lijkt in alle andere ziekenhuizen. Voorwaarde is dat de opleiders hier open voor staan. Bespreking in een centrale opleidingsvergadering kan dit bevorderen. Het lijkt ons verstandig de beoordelingen in een vooraf vastgestelde periode te doen met een duidelijke deadline.

Uit de literatuur is bekend dat opleiders die feedback hebben gekregen op hun opleidingskwaliteiten bij een volgende beoordeling vaak verbetering tonen.13-14 2122 De grootste verbetering is zichtbaar bij degenen die de eerste keer onder het gemiddelde scoren. Het blijkt dat na herhaalde beoordelingen vooral het geven van feedback door de specialisten blijft toenemen, een eigenschap die door artsassistenten zeer gewaardeerd wordt.21 Wij zien het belang van deze beoordelingen vooral in educatieve zin, voor zowel de opleiders als de arts-assistenten. Of er in Deventer ook een verbetering bij de opleiders waarneembaar is, moet nog blijken. Binnenkort zal een nieuwe beoordelingsronde opgestart worden. 
De arts-assistenten gaven aan dat het invullen van de vragenlijst over het proces van leren van de verschillende competenties niet alleen het inzicht in de taken van de opleider bevorderde, maar ook in de competenties die hij zichzelf eigen moet maken. Het was de verwachting grote verschillen te vinden in de manier waarop de zeven competenties worden geleerd. Het blijkt echter dat docenten een belangrijke invloed hebben op al het leren van de artsassistent, zowel in de meester-gezel relatie (met name ten aanzien van medisch handelen) als via zijn voorbeeld als rolmodel (professionaliteit, management en maatschappelijk handelen).

\section{Conclusie}

Het aangepaste beoordelingsinstrument is bruikbaar voor specialistenopleidingen. Gestructureerde feedback geven aan opleiders is een positieve ervaring voor beide partijen. De opleiders krijgen commentaar op hun persoonlijk functioneren en inzicht in hun invloed als rolmodel. Het ontvangen en geven van feedback tussen opleiders en arts-assistenten bevordert een atmosfeer van kwaliteitsverbetering die het onderwijs en mogelijk ook de patiëntenzorg ten goede komt.

Belangenconflict: geen gemeld.

Financiële ondersteuning: geen gemeld.

\section{Summary}

Introduction: There is a growing interest in assessing the teaching skills of medical faculty involved in postgraduate training programmes with the aim of improving specialty training. Deventer Hospital has introduced a procedure whereby junior doctors in training assess the teaching skills of medical staff by means of a questionnaire.

Method: A questionnaire was designed containing 28 questions about the teaching performance of staff members. The trainees discussed the results of the questionnaire with each individual member of staff. The content of the questionnaire was evaluated afterwards. At the same time the trainees were asked how they acquired the seven competencies required by the Dutch Central College of Medical Specialities.

Results: Forty-five trainees in seven different specialties participated. The questionnaire appeared to be feasible for assessing staff members. The questionnaire was evaluated and some modifications were made. Trainees turned out to acquire different competencies in the same ways: the apprentice model, role modelling by staff and the trainee's personal experience.

Discussion: The modified questionnaire proved to be suitable for appraisal interviews of staff members' teaching skills. The interviews were perceived as a positive experience for both parties. There is evidence from the literature that repeated assessment leads to improvements in medical specialists' teaching performance. The assessments will have to be repeated in the future to determine whether they are effective.

Conclusion: The questionnaire is useful for junior doctors in the training programmes of different specialties. Giving structured feedback proved to be a positive experience for both teachers and trainees. (Flikweert ER, Miedema MT, Briët JW. Assessment of clinical faculty as teachers by junior doctors in training. Dutch Journal of Medical Education 2007;26(1):3-10.)

\section{Literatuur}

Penders G, Dijk N van, Doelder B de. Meester en gezel: op zoek naar verbeteringen in de rol van klinisch docent. Tijdschrift voor Medisch Onderwijs 2002;21:195-200.

Fincher RM, Simspon DE, Mennin SP, Rosenfeld GC, Rothman A, McGrew MC, et al. Scholarship in teaching: an imperative for the 21st century. Acad Med 2000;75:887-94.

Hesketh EA, Bagnall G, Buckley EG, Friedman M, Goodall E, Harden RM, et al. A framework for developing excellence as a clinical educator. Med Educ 2001;35:555-64.

Irby DM. What clinical teachers in medicine need to know. Acad Med 1994;69:333-42.

Metz JC, Zwierstra RP, Fluit CR, Scherpbier AJ. Didactische en onderwijskundige scholing van docenten geneeskunde. Ned Tijdschr Geneeskd 1996;140:894-6.

Beckman TJ, Lee MC, Rohren CH, Pankratz VS. Evaluating an instrument for the peer review of inpatient teaching. Med Teach 2003;25:131-5.

Copeland HL, Hewson MG. Developing and testing an instrument to measure the effectiveness of clinical teaching in an academic medical center. Acad Med 2000;75:161-6.

Roff S, McAleer S, Skinner A. Development and validation of an instrument to measure the postgraduate clinical learning and teaching educational environment for hospital-based junior doctors in the UK. Med Teach 2005;27:326-31.

Ko CY, Escarce JJ, Baker L, Sharp J, Guarino C. Predictors of surgery resident satisfaction with teaching by attendents: a national survey. Ann Surg 2005;241:373-80.

Zwierstra RP, Fick TE. Trainingen voor klinische docenten. Tijdschrift voor Medisch Onderwijs 2004;23:51-6.

Keemers-Gels M, Nienhuijs S, Barendregt W, Bruggink E, Srobbe L. Stafleden op rapport. Med Contact 2004;8:273-5.

Bleker OP, Cate ThJ ten, Holdrinet RSG. De algemene competenties van de medisch specialist in de toekomst. Tijdschrift voor Medisch Onderwijs 2004;23:4-14.

Cohen R, MacRae H, Jamieson C. Teaching effectiveness of surgeons. Am J Surg 1996;171:612-4.

Maker VK, Curtis KD, Donelly MB. Faculty evaluations: diagnostic and therapeutic. Curr Surg 2004;61:597-601.

Wright SM, Kern DE, Kolodner K, Howard DM, Brancati FL. Attributes of excellent attendingphysician role models. N Engl J Med 1998; 339:1986-93.

Verma S, Flynn L, Seguin R. Faculty's and residents' perceptions of teaching and evaluating the role of health advocate: a study at one Canadian university. Acad Med 2005;80:103-8.

Maker VK, Curtis KD, Donnelly MB. Are you a surgical role model? Curr Surg 2004;61:111-5.

Skeff KM, Mutha S. Role models - guiding the future of medicine. N Engl J Med 1998;339:2015-7.

Cox SS, Swanson MS. Identification of teaching excellence in operating room and clinic settings. Am J Surg 2002;183:251-5.

Verkerk M, Bree M de, Jaspers F. Reflectieve professionaliteit. Naar een invulling van het CCMScompetentiegebied 'professionaliteit'. Tijdschrift voor Medisch Onderwijs 2005;24:162-7.

Maker VK, Lewis MJ, Donelly MB. Ongoing faculty evaluations: developmental gain or just more pain? Curr Surg 2006;63:80-4.

Schum TR, Yindra KJ. Relationship between systematic feedback to faculty and ratings of clinical teaching. Acad Med 1996;71:1100-2. 